\title{
El falsacionismo de Popper y sus objeciones al marxismo
}

Popper's fasificationism and his objections to marxism

\author{
Carlos Miguel Tovar Samanez \\ Universidad Nacional Mayor de San Marcos, Lima, Perú \\ Contacto: carlos.tovar3@unmsm.edu.pe \\ https://orcid.org/0000-0002-8640-6276
}

\section{Resumen}

El método falsacionista de Popper establece criterios de demarcación entre ciencia y metafísica, y propone un procedimiento para someter a prueba la validez de las teorías científicas. Desde su punto de vista epistemológico, Popper formula críticas al marxismo, al que descalifica con variados argumentos. Este trabajo se propone analizar dicha argumentación y determinar en qué medida es posible, utilizando las propias herramientas proporcionadas por Popper, validar el método marxista, su capacidad de formular leyes científicas, de hacer predicciones fundadas en esas leyes y de resistir la comprobación histórica de las mismas.

Palabras clave: Falsacionismo; Ciencia; Marxismo; Predicciones; Métodos.

\begin{abstract}
Popper's falsificationist method establishes criteria for demarcation between science and metaphysics, and proposes a procedure to test the validity of scientific theories. From his epistemological standpoint, Popper formulates critics to Marxism, and disapproves it with several arguments. This paper has the aim to analyze that argumentation and to determine if it is possible, using the same tools supplied by Popper, to validate the Marxist method, its capacity to formulate scientific rules, to make predictions founded in such rules and to resist the historical testing of those forecasts.
\end{abstract}

Keywords: Falsificationism; Science; Marxism; Predictions; Methods.

Recibido: 10.08.17

Aceptado: 05.05.19

\section{El método falsacionista}

Desde el epicentro de los acalorados debates epistemológicos del siglo XX, Karl Popper (1902-1994) elabora una propuesta metodológica que parece querer superar el entrampamiento entre quienes defendían la validez de la evidencia empírica en las ciencias naturales y quienes la cuestionaban. Si bien Popper participa, con estos últimos, del criterio de que la lógica inductiva presentaba dificultades que, hasta entonces, parecían insuperables, no se resigna a admitir el 
supuesto desmoronamiento del edificio positivista trabajosamente levantado por los analíticos y, especialmente, por los integrantes del célebre Círculo de Viena $(1980 ; 1994 ; 2010)$. Como racionalista crítico, reafirma su creencia en la validez del progreso científico, y dice que los positivistas lógicos, en su afán de aniquilar la metafísica, terminan por aniquilar la ciencia natural.

Popper elabora entonces un método que podría calificarse de ecléctico, puesto que incorpora el valor de la experimentación (aunque solo sea para “contrastar" las teorías), de la deducción lógica (el uso del modus tollens, por ejemplo), de la intuición para la formulación de hipótesis y enunciados, e incluso de la intersubjetividad como criterio de validez.

El núcleo del método popperiano puede expresarse en los dos sustantivos con los que titula uno de sus libros: Conjeturas y refutaciones (1994). El trabajo de la ciencia, para él, consiste en la formulación de hipótesis (conjeturas) y la especificación precisa de los experimentos o pruebas a las que dichas hipótesis han de someterse para comprobar su validez (refutaciones).

Si bien la observación de cinco mil (o quinientos mil) cisnes blancos no proporciona ninguna certeza para decir que todos los cisnes son blancos, y bastará la aparición de un solo cisne negro para echar por tierra esa pretensión, ello no significa — dice Popper - que la experimentación científica carezca de utilidad. Sirve para contrastar las teorías con la realidad empírica, no para "verificarlas" (se cuida de utilizar esta palabra), sino para ir limpiando a la ciencia de errores, mediante el método de la "falsación".

Sin embargo, para que esta "falsación" pueda llevarse a cabo correctamente, las teorías científicas deben seguir ciertas reglas de racionalidad en su construcción.

1) Deben poseer una estructura lógica en sus conclusiones, usando para ello procedimientos deductivos correctos.

2) Deben tener una estructura general bien conformada, sea que predomine en ella la forma lógico-deductiva o la forma empírica. 
3) Deben ser comparadas con otras teorías existentes, para saber en qué medida se apoyan en ellas o las contradicen.

4) Deben especificar experimentos cruciales que permitan contrastarlas con la realidad, señalando claramente las condiciones precisas en las que dichos experimentos permitirán "falsar" las hipótesis.

Cumplidos estos requisitos, se procede a la contrastación empírica de las hipótesis. Si el resultado de los experimentos es negativo, se dice que la teoría ha sido falsada. Si es positivo (es decir, si el experimento produce el resultado pronosticado), no se dice que la teoría haya sido "verificada", sino que "ha demostrado su temple" o que ha sido "corroborada" ("por esta vez", anota Popper, para enfatizar que la misma teoría podría ser, tarde o temprano, refutada).

Podría objetarse que, para Popper, las teorías que soportan los procedimientos de contrastación quedan en una especie de limbo que no es ni verdadero ni falso, suspendidas a la espera de otras sucesivas contrastaciones. Pero esa no es la idea del autor. Popper cree, como hemos dicho, en el progreso de la ciencia. Así, una teoría "falsada" generalmente es reemplazada por otra teoría mejor, y una teoría "corroborada" es, en todo caso, una vaso "medio lleno" y no uno "medio vacío"; de tal manera, mientras no se produzca la falsación definitiva, esa teoría sigue siendo una contribución al avance del conocimiento científico.

Si dejamos de lado objeciones menores al esquema de Popper, podemos decir del mismo que proporciona muy buenas herramientas para un análisis epistemológico de las teorías científicas. De esta forma, queremos utilizar dicho instrumental para averiguar si el marxismo soporta la prueba para calificarse como ciencia.

\section{Las objeciones epistemológicas de Popper}

Ocurre, sin embargo, que sobre esa cuestión ya existe — por parte de Popperuna opinión bastante formada. Con diversos argumentos, el gran filósofo austriaco descalifica al marxismo y lo excluye del campo científico. Pasaremos a resumir brevemente su razonamiento. 
Popper califica como "doctrinas historicistas" al marxismo y a cualquier otra teoría que pretenda que las ciencias sociales pueden hacer predicciones científicas de la misma manera en que lo hacen las ciencias naturales (Popper, 1994). Dice que esa creencia (errónea, según él) se fundamenta en la idea equivocada de que la historia de la humanidad sigue una trama y que podemos, por consiguiente, desentrañar esa urdimbre para encontrar las claves del futuro. Para Popper, esa pretensión se traduce en el afán de hacer "profecías históricas incondicionales" en lugar de limitarse, como deberían, a hacer "predicciones científicas".

Encontramos, entonces, que ya no es tan tajante la negativa inicial de Popper. No es que no se puedan hacer predicciones, sino que estas deben ser - como todas las que hace la ciencia - condicionales. No podemos decir "tal cosa ocurrirá" en términos absolutos. Así como la física nos enseña que, en determinadas condiciones, una caldera estalla, de la misma manera las ciencias sociales pueden perfectamente decir que, en condiciones específicas, ocurrirá cierto fenómeno.

A continuación, Popper da otro paso y dice que, sobre la base de predicciones condicionales, las ciencias naturales pueden derivar otras predicciones, inclusive incondicionales. Pero las ciencias sociales, según nuestro autor, no pueden hacer la misma cosa. No es posible derivar profecías a largo plazo a partir de predicciones condicionales, dice Popper, porque tales profecías solo se aplican a sistemas recurrentes o repetitivos (Popper, 1994). Es posible predecir eclipses, dice, porque nuestro sistema solar es repetitivo, y esa repetición no está alterada por interferencias exteriores.

Sin embargo, la sociedad humana - dice Popper - no es repetitiva en los grandes procesos históricos, razón por la cual las ciencias sociales no pueden profetizar. Para él, resulta ingenuo creer que los seres humanos actúan como parte de los grandes conjuntos sociales como, por ejemplo, las clases. Existen, dice, conjuntos como una multitud reunida en determinado sitio, y tales conglomerados pueden actuar, eventualmente, como grupos con determinado comportamiento empírico. Pero no existe, según el autor, nada que pueda llamarse, por ejemplo "la clase media". Tal cosa no pasa, para Popper, de ser una mera suposición teórica. 
Popper admite, no obstante, que las ciencias sociales pueden predecir "las consecuencias inesperadas de las acciones humanas intencionales". Cita como ejemplo el que si las personas compran casas en determinado distrito, subirán los precios de los inmuebles en tal lugar. Concuerda con Marx en que el capitalista no es un "conspirador demoníaco", sino un hombre obligado por las leyes del sistema económico a hacer lo que hace. Admite, entonces, que hay determinadas leyes o reglas que hacen que "todos estemos atrapados" en la red del sistema social.

No podría negarlo sin desautorizar al mismo tiempo la propia doctrina liberal que él profesa, puesto que no fue Marx quien se dio cuenta de la existencia de esas "leyes de hierro" que nos atrapan, sino Adam Smith, como bien lo ha señalado Terry Eagleton (2011). Pero Popper deduce, a partir de allí, que la tarea de las ciencias sociales consiste solamente en establecer reglas tecnológicas prácticas que adviertan lo que "no podemos hacer".

Ocurre que, llegados aquí, la demarcación que Popper procura establecer se vuelve tan sutil que casi se desvanece. Si podemos predecir consecuencias inesperadas de las acciones humanas, ¿por qué no podríamos pronosticar, igualmente, otras consecuencias deseables o esperables? También se desvanece el límite entre los comportamientos de "una multitud reunida en cierto lugar" y "una gran cantidad de compradores de casas que hacen elevar el precio de las mismas en cierto distrito" o, inclusive, "la clase de trabajadores industriales asalariados de determinado país"; ello en el sentido de que, si es posible establecer las condiciones en que cualquiera de estos colectivos desarrolla sus acciones, también es viable, en principio, predecir sus comportamientos, precisamente porque - como Popper admite - "estamos todos atrapados dentro de las leyes del sistema social". La cuestión se reduce, entonces, a un estudio objetivo de las condiciones sociales que determine hasta qué punto, en cada caso, es posible encontrar la repetición de ciertas condiciones sociales de manera que sea posible formular predicciones acerca de los efectos que dichas condiciones repetitivas van a producir.

En este punto, sin embargo, Popper cae en una confusión llevado, al 
parecer, por un afán de establecer un paralelo entre estas predicciones de hechos “indeseados", por una parte, y el famoso modus tollens que el autor propone como procedimiento lógico de falsación.

Las teorías científicas no dejan nunca de ser, según el filósofo austriaco, conjeturas imposibles de ser verificadas fehacientemente. Lo único que puede hacerse es refutarlas mediante el modus tollens. Si decimos que dada una premisa ocurrirá determinado hecho y luego se constata que tal hecho no ocurre, decimos que la premisa ha sido refutada. Pero eso es algo muy distinto de "predecir las consecuencias indeseadas" de nuestras acciones. No existe ninguna equivalencia entre ambas cosas.

La razón es muy simple: si somos capaces de predecir las consecuencias indeseadas de nuestras acciones, entonces somos igualmente competentes para pronosticar efectos deseados o deseables. Si podemos predecir que comprando una casa hacemos, sin desearlo, que suban los precios en el barrio, de la misma manera un vendedor de inmuebles puede, mediante propaganda, hacer que acudan al barrio más compradores, obteniendo con ello la consecuencia deseada de que suban los precios. Otro ejemplo citado por Popper: "sin aumentar la productividad, no se puede elevar el salario real de la clase trabajadora". El filósofo parece creer que, haciendo solamente predicciones de cosas indeseadas, se mantiene fiel a su posición falsacionista. Pero en este caso, como en el anterior, es perfectamente posible formular la predicción equivalente en función de lo deseable: "si aumentamos la productividad, será posible elevar los salarios reales de los trabajadores". Es significativo, además, que Popper, al ver en este caso solo un lado de la moneda, ponga como ejemplo un enunciado que es un lugar común del pensamiento pro empresarial.

Las predicciones "indeseadas" de Popper no tienen nada que ver con la falsación que se lleva a cabo con el modus tollens, puesto que esas mismas predicciones "indeseadas", a su vez, pueden ser falsadas, de la misma manera como las predicciones "deseadas" también pueden serlo.

La crítica de Popper hacia el historicismo se vincula con otra postura, 
llamada nominalismo ontológico (Beltrán, 1991). Esta rechaza reconocer la existencia de grandes sujetos colectivos (clases sociales, civilizaciones, etc.) porque esos llamados conjuntos sociales no pasan de ser meros postulados, ideas arraigadas en las teorías sociales populares o creencias del colectivismo ingenuo, pero carentes de sustento científico. Lo que cabe, según este autor, es analizar los fenómenos sociales, incluso los colectivos, en función de los individuos y sus acciones y relaciones (Popper, 1994).

Por cierto, la postura de Popper no es tan extrema. El filósofo austriaco sí acepta que las ciencias sociales tienen la capacidad de predecir fenómenos $\mathrm{y}$ acontecimientos, aunque en una escala mucho menor que la que pretende el 'historicismo'.

Sin embargo, luego de desarrollar este hilo de razonamientos, Popper dictamina, de manera inapelable, que la doctrina que él llama historicista ha sido eliminada y, con ello, se ha provocado "el derrumbe total del marxismo" en lo que respecta a sus pretensiones de ser considerado una ciencia. Hablando de "repercusiones inesperadas de nuestras acciones", ocurre que Popper, sin quererlo, ha proporcionado al marxismo muy buenos argumentos para defenderse, en lugar de haberlo demolido hasta sus cimientos, como cree.

\section{La crítica política}

Las críticas de Popper no terminan en el punto anterior, pero lo que viene a continuación ya no constituye, según el propio filósofo reconoce, una descalificación del marxismo como ciencia, sino una crítica del mismo como teoría política. Se refiere, por ejemplo, a la pretensión de que solo una revolución social puede crear las condiciones adecuadas para la vida de los seres humanos. Popper dice estar convencido de que las revoluciones destruyen, junto con la armazón institucional y tradicional de la sociedad que pretenden cambiar, el mismo conjunto de valores que dichos cambios revolucionarios pretenden conseguir (Popper, 1994). Los métodos revolucionarios, dice, solo consiguen empeorar las cosas, en lugar de mejorarlas. Una vez que se destruye la tradición, la civilización misma desaparece con ella. Algo así como tirar al bebé junto con el agua del baño. 
Dice también que las revoluciones no hacen más que reemplazar viejos amos opresores por otros nuevos, sin ninguna garantía de que estos últimos sean mejores. El problema no está en las personas, sino en las instituciones, y los marxistas - afirma Popper - "no piensan en instituciones", sino que depositan su fe en ciertas personalidades.

El problema de estas críticas políticas de Popper hacia el marxismo está en que su autor no se toma la molestia de presentar ningún sustento para ellas. Simplemente las enuncia, de manera apodíctica, contradiciendo así todo el edificio de su propio método científico. Por ello se ha dicho, con razón, que utiliza un doble estándar: uno muy severo para criticar al marxismo y su supuesta falta de rigor científico, y otro completamente informal para lanzar una serie de afirmaciones sin fundamento (Verikukis, 2007).

Si el propio Popper dice que no es posible encontrar, en la historia humana, regularidades que permitan hacer profecías, ¿cómo así puede afirmar, por ejemplo, que las revoluciones "solo pueden empeorar las cosas"? ¿No era que no se podían hacer profecías sobre este tipo de materias? ¿O es que el señor Popper está exonerado de cumplir sus propias reglas?

La revolución francesa, por ejemplo, abrió paso a la instauración del sufragio universal, la declaración de los derechos humanos y el régimen democrático representativo. ¿Son esas consecuencias peores que sus antecedentes, es decir, el régimen monárquico, la sociedad estamental, la servidumbre, etcétera? Es inimaginable que un liberal como Popper crea tal cosa. Por cierto, hubiera sido mucho mejor que las conquistas de la Revolución francesa se obtuvieran sin violencia, sin la guillotina ni el periodo del terror. Pero, a pesar de todo ello, la democracia sobrevino a la época del terror, y las cosas mejoraron en lugar de empeorar, como pronostica el fatalismo de Popper respecto de las revoluciones.

Tampoco es inevitable que las revoluciones utilicen métodos violentos. La reciente revolución pacífica de Islandia es una muestra formidable de esta posibilidad (Aldama, 2011). Tras la crisis financiera de 2008, los islandeses no aceptaron que el Estado, con el dinero de los ciudadanos, rescatara a los bancos 
defraudadores. Millares se manifestaron, pacífica y ordenadamente, para exigir el cambio de gobierno y una nueva Constitución, consiguiendo ambas cosas, además del enjuiciamiento y encarcelamiento de los estafadores de las finanzas. ¿No constituye todo ello una verdadera revolución?

\section{Falsabilidad y marxismo}

Al dejar de lado las críticas puramente políticas de Popper, nos queda, sin embargo - como hemos dicho líneas arriba-, un valioso instrumental proporcionado por este filósofo para someter al marxismo a un análisis o criterio demarcatorio. Mediante este se puede dilucidar si las teorías fundadas por Marx y Engels se encuentran dentro de los linderos de la ciencia o si, por el contrario, quedan excluidas de dicho campo.

Aplicando el método de Popper, corresponde entonces preguntarnos, en primer lugar, si el marxismo es un cuerpo de proposiciones lógicamente articuladas, de manera que, a partir de ciertas premisas, se obtengan determinadas conclusiones. En segundo lugar, si la forma general de la teoría marxista es coherente, sea que tenga un desarrollo predominantemente lógico-deductivo o más bien empírico. En tercer lugar, si el marxismo se apoya en los avances científicos obtenidos por ciertas teorías, si contradice a otras y, cualquiera que fuere el caso, si lo hace de manera fundamentada. Finalmente, en cuarto lugar, la parte más característica del método popperiano: si el marxismo es falsable, es decir, si formula determinadas predicciones y especifica las condiciones en las cuales dichos pronósticos pueden someterse a contrastación.

No podemos extendernos, dadas las limitaciones de espacio de este ensayo, en un recuento pormenorizado de las formulaciones del marxismo, y muchos menos hacerlo en cada uno de los libros, bastante numerosos por cierto, que Marx y Engels dejaron para la posteridad. Nos limitaremos entonces a hacer un breve repaso de algunas ideas.

Para Lenin, el marxismo es una teoría integrada por tres elementos: la filosofía alemana, el socialismo francés y la economía política inglesa (Lenin, 
1969). Apoyándonos en este punto de vista, nosotros precisaremos que el primer elemento integrante del marxismo es la filosofía materialista dialéctica, que constituye el fundamento conceptual sobre el que se desarrolla la parte científica. En términos generales, el materialismo dialéctico (una derivación izquierdista de la dialéctica idealista de Hegel) es una vertiente del realismo que afirma que las cosas están en permanente transformación, y que esta transformación se debe al desarrollo de las contradicciones que todas ellas encierran dentro de sí mismas y en su relación con las demás.

A continuación del materialismo dialéctico viene la segunda parte, denominada materialismo histórico, que analiza la estructura de las formaciones sociales a lo largo de la historia humana. Marx y Engels hicieron un largo y profundo estudio de la historia de las sociedades, desde el comunismo primitivo hasta el capitalismo, pasando por la sociedad esclavista y la sociedad feudal. Establecieron, a partir de dicho estudio, un conjunto de leyes científicas que rigen el acontecer histórico. Esas leyes establecen que las sociedades humanas se construyen sobre la base de su estructura económica, la que, a su vez, se conforma por la relación entre el desarrollo de las técnicas de producción (que Marx llama "fuerzas productivas") y las relaciones que los seres humanos establecen entre sí; en tal sentido, para establecer dichas relaciones parten de las condiciones de propiedad sobre los medios de producción (la tierra, las fábricas, las empresas comerciales, los bancos, etcétera). Este vínculo entre "fuerzas productivas" y "relaciones de producción" es, para el marxismo, la clave del desenvolvimiento de la historia humana (Marx y Engels, 1971a).

La tercera parte integrante del marxismo es la teoría económica propiamente dicha, producto - como explica Lenin - del estudio y la crítica que Marx hizo de la economía política inglesa. Partiendo de las premisas del materialismo histórico, Marx y Engels analizaron la sociedad capitalista de su época, para determinar cuáles eran las contradicciones que existían, dentro de dicho régimen económico, en esa crucial articulación entre las fuerzas productivas y las relaciones de producción. Marx desmenuzó hasta en sus menores detalles 
todo el mecanismo de la producción del capital, y pudo encontrar de manera precisa en qué aspecto de la reproducción del capital residía la contradicción principal (Marx, 1972).

Como se puede observar en este panorama sintético, hay una secuencia de proposiciones articuladas, empezando desde la filosofía materialista dialéctica, atravesando por las observaciones científicas del materialismo histórico, hasta llegar al estudio de la economía del capitalismo. Podemos decir que el marxismo cumple satisfactoriamente (en este panorama muy general, y detalles aparte) con las exigencias primera y segunda del método popperiano,

En lo que se refiere a la tercera, Marx y Engels, a partir de la filosofía hegeliana y del materialismo de otros filósofos alemanes e ingleses (Feuerbach, Locke y Bacon, por citar solo algunos), recogieron los avances del conocimiento científico de su tiempo, en el campo de la historia y las ciencias naturales, estableciendo también sus diferencias frente a otras teorías científicas como la de Darwin o la de Malthus. Finalmente, Marx abordó con profundidad el estudio de la economía política, asimilando los aportes de Stuart Mill, Adam Smith y David Ricardo, para luego hacer la crítica de los errores y limitaciones de estos autores y fundar sus propios postulados económicos. Hay, como podemos ver, una coherente relación entre la teoría marxista y la ciencia de su tiempo, lo que nos da fundamento suficiente para decir que el marxismo cumple con la tercera condición del método de Popper.

No obstante, la parte medular del método popperiano reside — como hemos dicho - en el cuarto requisito de la ciencia: la falsabilidad. Y es en este punto donde Popper concentra sus críticas a las teorías de Marx y Engels. La acusación central consiste en que el marxismo, según el filósofo austriaco, no formula las condiciones de uno o varios experimentos cruciales que permitan someterlo a contraste con la realidad, es decir, falsarlo. Agrava esto, según Popper, el hecho de que Marx, Engels y sus seguidores han hecho una serie de predicciones que la historia se ha encargado de refutar de manera contundente. Ante estos contrastes, los marxistas, lejos de rectificar sus teorías, han formulado una serie de hipótesis 
ad-hoc para acomodar los hechos a su pensamiento. Todo ello, según Popper, no hace sino corroborar el carácter no-científico de la teoría marxista.

Así como hemos desechado otras objeciones de Popper hacia el marxismo, nos toca ahora reconocer que esta última, que se refiere a la imposibilidad del falsar el marxismo, parece tener bastante fundamento. Pese a ello, sostenemos que esa supuesta infalsabilidad del marxismo puede ser subsanada buscando, en las propias elaboraciones teóricas de Marx y Engels, dónde se encuentran formuladas las predicciones fundamentales y cuáles serían, de acuerdo con ellas, las experiencias cruciales que pudieran falsarlas. Finalmente, habría que proceder a confrontar esas predicciones con la realidad para ver si han sido refutadas por ella o, en los términos de Popper, "corroboradas" (Unruhe, 2015).

\section{Predicción fundamental en el marxismo}

Dice el gran crítico Edmund Wilson (1972) que en los escritos de Marx hay pasajes más bien oscuros (en los que vuelve una y otra vez a la carga contra algún adversario, sin decidirse a soltar su presa), pero hay otros momentos que tienen "la capacidad iluminadora de una portentosa clarividencia". Tal vez el mayor de estos últimos sea el famoso prólogo a la Contribución a la crítica de la economía política, brillante resumen al que - dicen — no es posible cambiarle ni una coma (Marx y Engels, 1971a).

La historia humana está, para Marx, determinada en última instancia por la relación que se establece entre las llamadas fuerzas productivas materiales y las relaciones de producción, que se contraen en la organización social para el funcionamiento de esas fuerzas productivas. Dice Marx que

[...] al llegar a cierto grado de desarrollo, las fuerzas productivas materiales entran en contradicción con las relaciones de producción existentes. Dichas relaciones, que antes facilitaban el desarrollo de las fuerzas productivas, se convierten en una traba para las mismas. Se abre así una época de revolución social. (Marx y Engels, 1971a, p. 343)

Es importante prestar atención a este otro párrafo del mismo prólogo de Contribución...: 
Ninguna formación social desaparece antes de que se desarrollen todas las fuerzas productivas que caben dentro de ella, y jamás aparecen nuevas y más altas relaciones de producción antes de que las condiciones materiales para su existencia hayan madurado en el seno de la propia sociedad antigua. (1971a, p. 343)

Puede decirse que este enunciado encierra, al mismo tiempo, una predicción tácita y unas condiciones de refutación.

Sucede que Marx y Engels no se limitaron a enunciar, así en general como acabamos de citarlos, esas leyes científicas que rigen la historia humana. Se ocuparon también, para beneficio del tema que nos interesa, de lo que ocurría con la Rusia de los zares, donde un fuerte movimiento popular trataba de canalizar el descontento social para derrocar a la monarquía. Sostuvieron una nutrida correspondencia con los populistas rusos, entre quienes germinaba la idea de que en Rusia, no obstante era una nación atrasada, precapitalista, con una mayoría de masas campesinas, una burguesía muy incipiente y un muy escaso proletariado, era posible llevar a cabo una revolución socialista. Pensaban ellos que esa escasez de proletariado podía compensarse con la existencia de algo que — según creían - proporcionaba una buena base para el establecimiento del socialismo: la comunidad campesina.

Creían los populistas que las comunidades campesinas eran una característica particularísima de la sociedad rusa, y que entre los miembros de dichas comunidades existían relaciones de solidaridad y propiedad común de los bienes que permitirían que, sin pasar por el capitalismo, pudiera establecerse el socialismo.

En su correspondencia con los populistas, y sobre todo en el trabajo de Engels Acerca de las relaciones sociales en Rusia, consta que él y Marx se opusieron tajantemente a esa idea. En este último texto dice Engels:

Sólo al llegar a cierto grado de desarrollo de las fuerzas productivas de la sociedad, muy alto hasta para nuestras condiciones presentes, se hace posible elevar la producción hasta un nivel en que la liquidación 
de las diferencias de clase represente un verdadero progreso, tenga consistencia y no traiga consigo el estancamiento o, incluso, la decadencia en el modo de producción de la sociedad. Pero, sólo en manos de la burguesía, han alcanzado las fuerzas productivas ese grado de desarrollo. Por consiguiente, la burguesía es, también en este aspecto, una condición previa, y tan necesaria como el proletariado mismo, de la revolución socialista. Por tanto, quien sea capaz de afirmar que es más fácil hacer la revolución en un país donde, aunque no hay proletariado, no hay tampoco burguesía, demuestra exclusivamente que debe aún estudiar el abecé del socialismo. (Marx y Engels, 1971b, p. 43)

Podemos extraer, del párrafo anterior, la predicción que se encuentra tácita en él, y que se puede formular de la manera siguiente:

(P) Si se pretende eliminar las diferencias de clase (esto es, establecer el socialismo) en una formación social donde no se ha alcanzado todavía el grado de desarrollo de las fuerzas productivas necesario para ello, sobrevendrá finalmente el estancamiento e, incluso, la decadencia en el modo de producción.

A mayor abundamiento, dice Engels que pretender instaurar el socialismo en un país donde no están dadas las condiciones para ello es desconocer el abecé del socialismo. En otras palabras, sería ignorar las leyes fundamentales que rigen la historia, esas mismas leyes que están claramente enunciadas en el citado prólogo de la Contribución a la crítica de la economía política.

\section{Experimento crucial}

Lo dicho líneas arriba nos sirve para fundamentar el razonamiento clave de este trabajo. Si Marx y Engels se aferraron con tanta fuerza a ese abecé de las leyes científicas que, luego de estudiar y analizar la historia humana decían haber descubierto, nos estaban entregando, indirectamente, las condiciones de refutación o falsación de su teoría.

En otras palabras: si la revolución rusa lograba establecer y hacer perdurar en ese país un sistema socialista, los hechos habrían venido a contradecir el abecé de la teoría. La teoría no habría sido, entonces, capaz de resistir lo que 
Popper llama un experimento crucial, y habría quedado falsada.

Las ciencias sociales, a diferencia de las ciencias naturales, no disponen de la facilidad de aislar elementos para someterlos a pruebas de laboratorio. Disponen, sin embargo, de un único laboratorio gigante: los acontecimientos de la historia misma. Y en ese escenario, la revolución rusa reúne, para el marxismo, todos los requisitos para ser considerada el experimento crucial, dramático y grandioso, que atañe a las hipótesis centrales de la teoría; tanto así que Marx y Engels, pese a todas las dudas y cuestionamientos que les hicieron, decidieron mantenerse firmes en este punto.

Ese fue también el punto de vista de Vladimir Lenin, el principal conductor de la Revolución bolchevique, quien era muy buen estudioso del marxismo y fiel continuador de las tesis de los fundadores. En completa consonancia con ellos, dice Lenin:

Los marxistas están absolutamente convencidos del carácter burgués de la revolución rusa. ¿Qué significa esto? Esto significa que las transformaciones democráticas en el régimen político y las transformaciones económico-sociales, que se han convertido en una necesidad para Rusia, no sólo no implican de por sí el socavamiento del capitalismo, el socavamiento de la dominación de la burguesía, sino que, por el contrario, desbrozarán por primera vez el terreno como es debido para un desarrollo vasto y rápido, europeo y no asiático, del capitalismo. (1969, p. 72)

A partir de entonces, hay un complejo derrotero que, por razones de extensión, no podemos detallar aquí, pero que señalaremos en muy grandes rasgos:

1) Marx, Engels y Lenin consideraron que, no obstante las condiciones sociales de Rusia no constituían una base suficiente para instaurar el socialismo en ese país, una eventual revolución socialista en los países de Europa occidental (revolución que, por entonces, se consideraba altamente probable) sí haría factible que, con el influjo de esa corriente revolucionaria, el socialismo europeo se "extendiese" a Rusia, por una 
especie de "efecto dominó". Esa sería, entonces, la única posibilidad de que Rusia transitase directamente de la semifeudalidad al socialismo.

2) En 1917 Lenin decide tomar el poder e instaurar el socialismo en Rusia, tras calcular que se avecinaba la revolución socialista en Europa occidental, especialmente en Alemania.

3) En 1921, visto que tal revolución europea no había ocurrido, Lenin, en consonancia con la teoría del materialismo histórico, retoma el camino originalmente planeado para Rusia y anuncia la Nueva Política Económica (NEP) que traza claramente un derrotero de desarrollo capitalista para ese país.

4) En 1924 muere Lenin y Stalin (1972), que hasta entonces había estado alineado con él (y ambos contra Trotsky), comienza un largo giro que concluye con el establecimiento del socialismo en Rusia. Considerando que en tales condiciones no se contaba con el esperado apoyo de un eventual socialismo europeo occidental, el establecimiento del socialismo en Rusia, llamado por Stalin "socialismo en un solo país", contradecía la teoría marxista, como acabamos de ver.

5) El régimen de capitalismo monopolista de Estado (Martín, 2007) que se estableció en Rusia (y otras naciones en la esfera de dominio de aquella) fue, por muchos años, eficiente para impulsar un espectacular desarrollo de las fuerzas productivas. Se implanta la industria pesada, se eleva el nivel de vida y educación del pueblo y se produce un salto tecnológico que permite a la Unión Soviética competir con los Estados Unidos, e incluso superarlos, como primera potencia mundial.

6) Pero la pretensión de implantar el socialismo, sin que existiera para ello una base proletaria suficiente, hace posible que una burocracia estatal y partidaria vaya sustituyendo a la clase trabajadora en el control del poder, y tienda a sofocar, a la larga, el propio desarrollo de las fuerzas productivas. 
7) Sobreviene la revolución tecnológica del último cuarto del siglo XX. La Unión Soviética, que hasta entonces se encontraba a la par con los Estados Unidos, no puede, sin embargo, canalizar los adelantos más significativos (la computadora personal es la innovación emblemática de esta etapa) para que estén al alcance de las grandes masas. Los inventos quedan en manos de una tecnocracia.

8) En occidente, la computadora personal, y posteriormente la Internet, impulsan una nueva etapa de intenso desarrollo capitalista y una liberalización de los mercados. Los ciudadanos tras la "Cortina de Hierro" pierden la fe y confianza en lo que conocían como "socialismo" y anhelan y codician el modo de vida y los beneficios de los que gozan los occidentales. Se cumple el enunciado del materialismo histórico que dice que "las relaciones de producción, que antes facilitaban el crecimiento de las fuerzas productivas, se convierten en una traba para las mismas", con lo que "se abre una época de revolución social".

9) Se disuelve la Unión Soviética y sobreviene una erosión generalizada de los sistemas "socialistas" satélites de esa potencia, que culmina en el desplome de los gobiernos, los cuales colapsan o "implosionan" sin encontrar prácticamente ninguna resistencia. Cae el Muro de Berlín y se abre paso a un crecimiento desordenado del capitalismo.

El proceso que acabamos de reseñar merece, por supuesto, un desarrollo mucho más amplio, que no es posible aquí por limitaciones de espacio. Nuestro argumento central consiste en que la Revolución rusa, considerada como experimento crucial del marxismo, confirma la predicción (P) de sus fundadores en el sentido de que

[...] si se pretende eliminar las diferencias de clase (esto es, establecer el socialismo) en una formación social donde no se ha alcanzado todavía el grado de desarrollo de las fuerzas productivas necesario para ello, sobrevendrán finalmente el estancamiento e, incluso, la decadencia en el modo de producción. (Marx y Engels, 1971b, p. 43; mis cursivas) 
Se presenta, así, una contradicción entre las fuerzas productivas y las relaciones de producción. Estas últimas, que hasta entonces habían facilitado el crecimiento de las fuerzas productivas, se convierten, tal como lo dice el enunciado del materialismo histórico, en una traba para las mismas. Se abre una época de revolución social, que tendrá su desenlace en el desplome del régimen del llamado "socialismo realmente existente". La hipótesis ha sido sometida a contrastación o, para decirlo en términos popperianos, ha soportado la falsación.

\section{Referencias bibliográficas}

Aldama, O. (9 de marzo de 2011). Por un mundo justo [Mensaje en un blog]. Recuperado de http://porunmundojusto.blogspot.com/2011/03/islandiarevolucion-silenciosa-pero.html.

Beltrán, M. (1991). La realidad social. Madrid: Tecnos.

Eagleton, T. (2011). Por qué Marx tenía razón. Barcelona: Península.

Lenin, V. I. (1969). Obras Escogidas. Moscú: Editorial Progreso.

Martín, V. O. (2007). La transformación del paisaje agrario: papel de las reformas agrarias en los países subdesarrollados. Nimbus, 19-20(155), 143-179.

Marx, K. (1972). El Capital. Ciudad de México: Fondo de Cultura Económica.

Marx, K. y Engels, F. (1971a). Obras escogidas, tomo I. Moscú: Editorial Progreso.

Marx, K. y Engels, F. (1971b). Obras escogidas, tomo II. Moscú: Editorial Progreso.

Popper, K. (1980). La lógica de la investigación cientifica. Madrid: Tecnos.

Popper, K. (1994). Conjeturas y refutaciones. Barcelona: Paidós Ibérica.

Popper, K. (2010). La sociedad abierta y sus enemigos. Barcelona: Paidós Ibérica.

Stalin, J. (1972). El socialismo en un solo país. En G. Procacci, Socialismo en un solo país. Córdoba: Cuadernos de Pasado y Presente. 
Unruhe, J. (6 de septiembre de 2015,). Was Karl Popper Right about Karl Marx? Yes and No. Recuperado de https://maoistrebelnews.com/2015/09/06/ was-karl-popper-right-about-karl-marx-yes-and-no/.

Verikukis, H. (2007). Popper's Double Standard of Scientificity in Criticizing Marxism. Recuperado de http://citeseerx.ist.psu.edu/viewdoc/download ?doi=10.1.1.550.1771\&rep=rep1\&type=pdf.

Wilson, E. (1972). Hacia la estación de Finlandia. Madrid: Alianza Editorial. 